International Journal of Current Advanced Research

ISSN: O: 2319-6475, ISSN: P: 2319 - 6505, Impact Factor: SJIF: 5.995

Available Online at www.journalijcar.org

Volume 6; Issue 3; March 2017; Page No. 2534-2538

DOI: http://dx.doi.org/10.24327/ijcar.2017.2538.0044

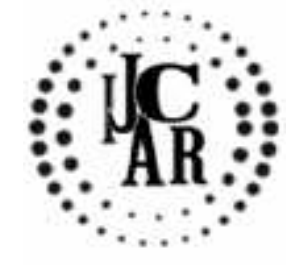

Research Article

\title{
ROLE OF COMMUNITY HEALTH NURSE AS A CHANGE AGENT
}

\section{Karthika S}

Department Of Community Health Nursing, M.M.I.N, Mmu, Mullana, Ambala, Haryana

\begin{tabular}{|c|c|}
\hline 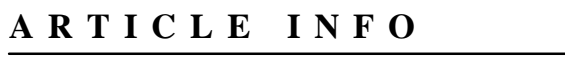 & A B S T R A C T \\
\hline Article History: & \multirow{8}{*}{$\begin{array}{l}\text { To be a leader is to effect change in people's behaviors. When nurses suggest that families } \\
\text { adopt healthier communication patterns, they are asking them to change. Teaching } \\
\text { parenting skills to teenagers is introducing a change. Promoting a community's self- } \\
\text { determination in choosing a safer environment requires that the individuals involved must } \\
\text { change. Because community health nursing's responsibility is to accomplish health goals } \\
\text { and thus promote change, nurses cannot lead without introducing change into people's } \\
\text { lives. Therefore it becomes imperative for community health nurses to understand the } \\
\text { nature of change, how people respond to it and how to effect change for improved } \\
\text { community health. Nurses can assist community clients to develop the four power sources } \\
\text { for themselves; using their position, capitalizing on personal characteristics, developing } \\
\text { expertise and taking advantage of opportunities. To promote client's self esteem, nurses } \\
\text { can provide consistent affirmations, set clear expectations, encourage increasing } \\
\text { responsibilities, model empowering behavior, facilitate client choices, and promote a sense } \\
\text { of meaning and hope. If they are not act in a positive way the nurse may need to use } \\
\text { persuasive or coercive power bases to protect them and the people affected by their actions. }\end{array}$} \\
\hline Received $18^{\text {th }}$ December, 2016 & \\
\hline Received in revised form $19^{\text {th }}$ January & \\
\hline Accepted $4^{\text {th }}$ February, 2017 & \\
\hline Published online $28^{\text {th }}$ March, 2017 & \\
\hline & \\
\hline Change, Change Agent, Community Health & \\
\hline Nurse, Power, Leader, Community, Client & \\
\hline
\end{tabular}

Copyright $\bigcirc 2017$ Karthika S. This is an open access article distributed under the Creative Commons Attribution License, which permits unrestricted use, distribution, and reproduction in any medium, provided the original work is properly cited.

\section{INTRODUCTION}

"One should bear in mind that there is nothing more difficult to execute, nor more dubious of success, nor more dangerous to administer than to initiate a new order of things"Machiavelli "The reasonable man adapts himself to the world; the unreasonable one persists in trying to adapt the world to himself. Therefore all progress depends on the unreasonable man"-G.B.Shaw The deliberate choice of historical quotations aims to show a number of introductory but key points regarding the phenomenon of change.

First and rather obviously change is not new. The factors which create and facilitate social change have been exercising philosophers', politicians' and managers' minds and skills the generations, yet the process of introducing innovative methods, systems or products does not appear to be any more understood or anymore successful today.

Secondly, change is not exclusive to nursing. Change is recognized as a constant feature of modern organizations and institutions, however in the last few years a number of policy documents from official nursing bodies have alluded, in their opening paragraphs, to the many and significant changes occurring in nursing.

*Corresponding author: Karthika S

Department Of Community Health Nursing, M.M.I.N, Mmu, Mullana, Ambala, Haryana
Thirdly, not all nurses are, can be or want to be change agents'. There are certain qualities and skills required that integrate notions of power and status; leadership, motivation and tenacity; high levels of communication, empathy \& conflict management; characteristics of foresight, creativity and planning as well as knowledge of research, evaluation and policies; and the obligatory practice of questioning the habitual and familiar.

\section{Definition}

Change is 'any planned or unplanned alteration of the status quo in an organism, situation or process'-Lippitt.

Change is the process of adopting an innovation.-Spardley \& Mc Curdy

Planned change is a 'deliberate and collaborative process involving a change agent and a system'-Brooten et.al

\section{Types of Change}

The way people respond to change depends partly on the type of change. The change process can be described as sudden or drastic (revolutionary) or gradual overtime (evolutionary)

Evolutionary change is change that is gradual and requires adjustment on an incremental basis. It modifies rather than replaces a current way of operating. e.g. becoming parents, gradually cutting back on the number of cigarettes smoked each day and losing weight by eliminating desserts and snacks. 
Because it is gradual, this kind of change does not require radical shifts in goals or values. Some people resist discarding their own ideas and accepting another's idea as it can reduce their self-esteem. Gradual change may 'ease the pain' that change brings to some individuals. This type of change sometimes may be viewed as reform.

Revolutionary change is a more rapid, drastic and threatening type of change that may completely upset the balance of system. E.g., sudden unemployment, stopped smoking overnight, losing the town's football team in a plane accident, suddenly removing children from abusive parents or suddenly replacing human workers with computers. In each instance, the people affected have little or no advance warning and little or no time to prepare. If the demands are too great, some may experience defense mechanisms such as incapacitation, resistance or denial of the new situation.

The impact of a proposed change on a system clearly depends on the degree of the change's evolutionary or revolutionary qualities, a factor to be considered in planning for change. A community in need of improved facilities for the handicapped (e.g. Ramps, wider doors) can introduce this change on an evolutionary, incremental basis, whereas a community that is involved in an unsafe, intolerable or life-threatening situation, such as a flood or serious influenza epidemic may require revolutionary change.

\section{Stages of Change}

It refers to the three sequential steps leading to change.

1. Unfreezing (when desire for change develops)

2. Changing (when new ideas are accepted and tried out)

3. Refreezing (when the change is integrated and stabilized in practice)

These stages were first described by Kurt Levin in the 1940s and early 1950s and have become a cornerstone for understanding the change process in more recent years.

Unfreezing: It occurs when a developing need for change causes disequilibrium in the system. People are motivated to change either intrinsically or by some external force. They have a sense of dissatisfaction they feel a void that they would like to fill. The unfreezing stage involves initiating the change.

Unfreezing may occur spontaneously.eg. A family requests help in solving a problem with alcoholism. A group seeks assistance in adjusting to retirement. A community desires a solution to noise pollution.

Role of change agent: the nurse as a change agent may need to initiate the unfreezing stage by attempting to motivate clients, through education or other strategies, to see the need for change.

Changing/moving: it occurs when people examine, accept and try the innovation. During this stage, people experience a series of attitude transformations, ranging from early questioning of the innovation's worth, to full acceptance and commitment, to accomplishing the change. E.g. when participants in a prenatal class are learning exercises or when elderly clients in a senior citizens center are discussing and trying ways to make their apartments safe from accidents.
Role of change agent: To help clients see the value of the change, encourage them to try it out and assist them in adopting it.

Refreezing: it occurs when change is established as an accepted and permanent part of the system. The rest of the system has adapted to it. Because it is no longer viewed as disruptive, threatening, or new, people no longer feel resistant to it. E.g.: when weight loss clients are routinely following their diets and losing weight. When senior citizens are using grab bars in their bathrooms and have removed scatter rugs from their homes. When a community has erected stop signs and established crosswalks at dangerous intersections. Refreezing involves integrating or internalizing the change into the system and then maintaining it.

Role of change agent: she must take special measures to ensure maintenance of the new behavioiur.

\section{Planned/Managed Change}

It is crucial to the development of successful community health programs. The following characteristics of planned change are key to its success.

1. The change is purposeful and intentional.

2. The change is by design, not by default.

3. Planned change in community health aims at improvement.

4. Planned change is accomplished through an influencing agent.

The planned change process involves a systematic sequence of activities that follows the nursing process. It begins when one recognizes a need. When the change agent fails to respond to a need for change, the need continues and may escalate.

Client system (those involves and effected by the change) and change agent must work together throughout the entire planned change process. Their respective roles vary depending on the situation and the player's abilities, but no planned change is truly effective without utilization of this collaborative relationship.

The client system which may be an entire community, will fluctuate in its involvement with the change process.(wavy arrow) fig 2

The change agent (straight arrow), as a good leader, analyzes the situation thoroughly, plans carefully and sets a steady course for effecting the change.fig 2

\section{Step 1: Recognize symptoms}

In this step, it is necessary to gather and examine the presenting evidence, not diagnose or jump ahead to treatment. For eg. Assume that a group of clients showing interest in receiving help with parenting skills.

The nurse must assess the specific needs to discover that some of the parents have trouble talking to their teenagers, others wonder whether their children's behavior is normal, a few question how strictly they should set limits, and still others are not certain about how to handle punishment.

\section{Step 2: Diagnose need}

First describe the situation as it is now (the real) and compare it with the way it should be (the deal). E.g. Land arguing and 
conflict may be normal and functional behavior for an adolescent support group. Hence there is no discrepancy between the real and the ideal. But when a need exists, a change effort is required. The next step is to determine the nature and cause of the need. Gathering data by questioning clients, checking the literature, or seeking consultation is important for making a more detail about diagnosis. The findings should be formulated into a single, diagnostic statement that also includes the cause.

Step 3: Analyze alternative solutions

Brain storming is helpful here, and the client system should be involved as much as possible in the process. Reviewing the literature is helpful at this point to suggest solutions tried by others. Make a list of all reasonable, broad alternatives and then analyze them thoroughly to determine the advantages, disadvantages, possible consequences and risks involved in each.

\section{Step 4: Select a change}

The risks involved in the choice of change should be reexamined, such as whether this action might be too costly in terms of time, money or potential for failure. Ways to reduce these risks might be explored. To know what the change is aiming to accomplish, a clearly stated goal should be formulated.

\section{Step 5: Plan the change}

At this stage, the change agent and client system together prepare the design and the blue print that guides the change action.

In steps through 4, data are gathered, a diagnosis is made, resources are assesses and a goal is established-all preparatory actions for planning the change. The plan tells the change agent and the client system how to meet the goal. During planning, it is useful to perform a force field analysis, a technique developed by Kurt Levin for examining all positive (driving) and negative (restraining) forces that are influencing a change situation.

\section{The steps for conducting force field analysis are as follows}

BRAINSTORM to produce a list of all driving and restraining forces.

1. Empric-rational (similar to technostructural, databased and communication related strategies.

2. Normative-reeducative (similar to educational, facilitative and persuasive strategies.

3. Power-coercive (similar to coercive strategy)

In a given situation, the change agent may use one or a combination of these STRATGIES to effect a change.

\section{Step 6: Implement the change}

At the start of implementation, be certain that all persons concerned clearly understand and are prepared for the change. The nurse must be sure that each member who will be affected by the proposed change understands 1 . What to expect 2 . The meaning of the change 3 . What will be required of them in adapting to it.

A pilot study can be done helps to test the change on a small scale, iron out problem, and revise the change before implementing it in the larger system.
Well written objectives with specific criteria for their measurement make the evaluation step simpler. The change agent makes needed modifications in the change before stabilization.

\section{Step 8: Stabilize the change}

A well-developed change plan includes a design for stabilization. The change agent actively encourages continued use of the innovation by establishing two-way communication, in this way, future resistance can be overcome, and the client's full commitment to the change can be maintained.

After stabilization occurs and the system achieves a new equilibrium, the change agent-client system relationship can be terminated for this specific change effort.

\section{Strategies to Facilitate the Process of Change}

There are 3 major change strategies,

1. Empric-rational (similar to technostructural, databased and communication related strategies.

2. Normative-reeducative (similar to educational, facilitative and persuasive strategies.

3. Power-coercive (similar to coercive strategy)

4. In a given situation, the change agent may use one or a combination of these stratifies to effect a change.

Empric- rational change strategies: this is used to effect change based on the assumption that people are ration and when presented with empric information, will adopt new practices that appeal to be in their best interest. Eg. Most family planning programs use empric-rational strategies. The difference lies in client ability and interest in self-help.

Normative-reeducative change strategies: this is used to influence change that not only present new information but directly influence people's attitudes and behaviours through persuasion. This approach strengthens client selfunderstanding, self control and commitment to new patterns through direct urging and influence. Eg. A health education program that aims to increase safety practices in an industrial setting not only provides information but also tells about individual rewards for safe practices.

Power-coercive change strategies: it use coercion based on fear to effect change. Change agents may derive power from, the law (health regulations, administrative policies), position (political, social or managerial), group (social, work or professional) and from personal power (personal charisma, competence, respect of followers). They use this power to coerce change; the result is forced compliance on the part of the client system.

\section{CONCLUSION}

Community health nurses introduce change every day that they practice. It requires using the principles of participation, resistance to change, proper timing, interdependence, flexibility and self-understanding. Every effort to solve a problem, prevent another problem from occurring, meet a potential community need, or promote people's optimal health requires changes. For these changes to be truly successful, so that desired outcomes are reached, they must be managed well. 


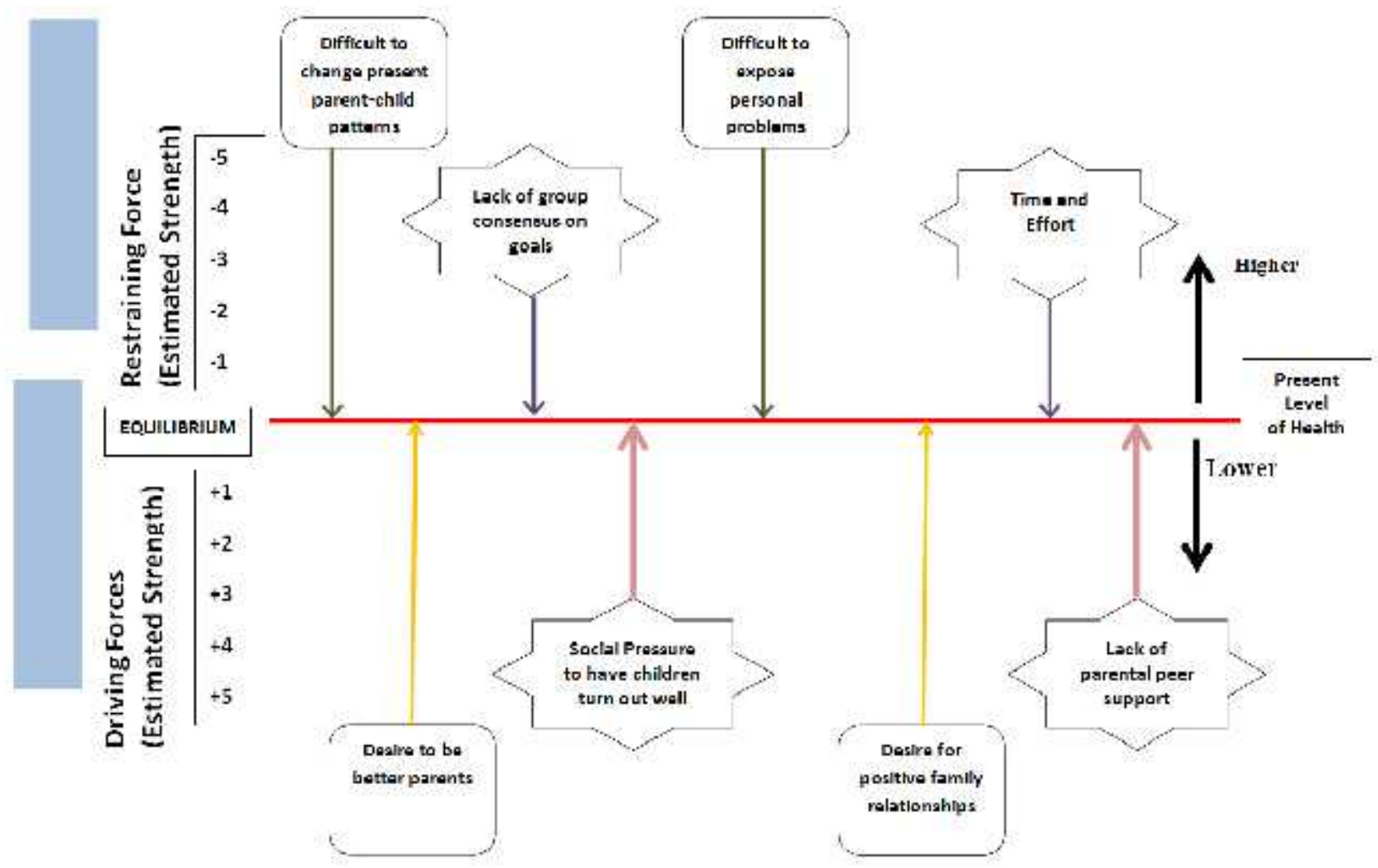

Figure.1 Analysis of Restraining and Driving Forces

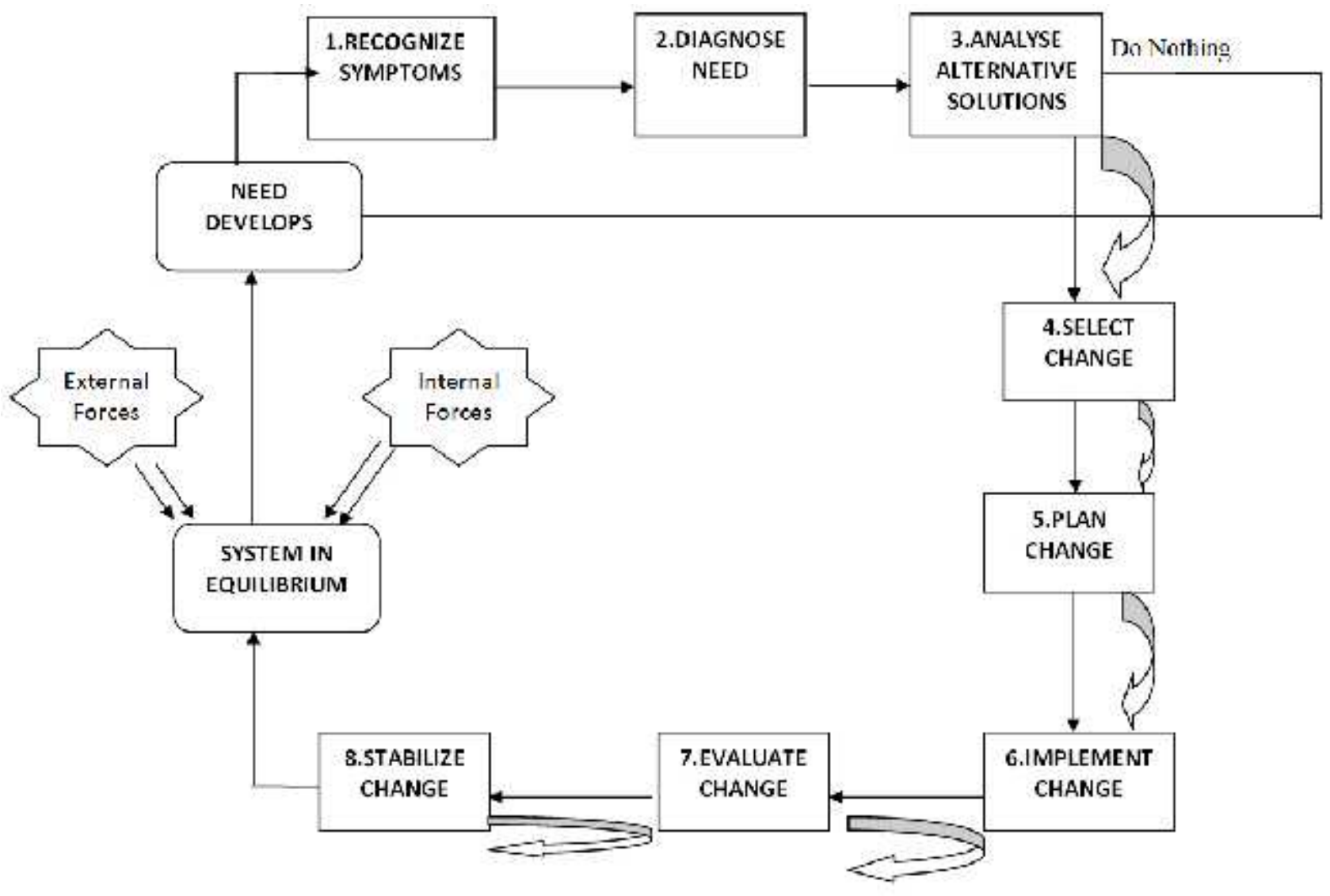

Figure 2 Planned Change Model 


\section{Bibliography}

1. Judith Ann Allender, community health nursing, $6^{\text {th }}$ edition, 2005, Lippincott Williams\& wilkins, Philadelphia, pg.no.314-323.

2. Burley, Contemporary community Nursing, Ist edition, 1997, Arnold publishers, New Delhi, pg.no.132-155.

3. Yurkovich E, 1990, Patient and nurse roles in the therapeutic community Perspect Psychiatr Care. 25(34):18-22.
4. Lessard et al, 2016, External facilitators and interprofessional facilitation teams: a qualitative study of their roles in supporting practice change. Implement Sci. Jul 16; 11:97.

5. Stefancyk et al, 2013, The nurse manager: change agent, change coach? Nurs Adm Q. Jan-Mar;37(1):13-7.

6. Hilz LM, 2000,The informatics nurse specialist as change agent. Application of innovation-diffusion theory. Comput Nurs.,Nov-Dec;18(6):272-8

7. Hriceniak J. et al. 1986, Hospice program development: the nurse as a change agent, Caring. Oct;5(10):44-8.

\section{How to cite this article:}

Karthika S (2017) ' Role of community health nurse as a change agent', International Journal of Current Advanced Research, 06(03), pp. 2534-2538.

DOI: http://dx.doi.org/10.24327/ijcar.2017.2538.0044 